\title{
Study on the Optimization of Nursing Education- Analysis of Professional Advantages and Training Difficulties of Male Nursing Students
}

\author{
Wang Mingming ${ }^{1, a}$ \\ ${ }^{1,2}$ School of Shandong Xiehe University \\ Jinan250109, China \\ a476398949@qq.com
}

\begin{abstract}
The main purpose of this study is to analyze the advantages of male nurses and practitioners in nursing education, the paper puts forward some effective measures to improve nursing education. This research uses the method of literature and interview to analyze the advantages of the male nurses to meet the needs of high-intensity work, the demand for the operation of the same sex and the demand for rational psychological quality, and analyzes the situation that the concept of female nurses is deeply rooted in the implementation of nurse education, which causes the psychological pressure of the male nurse, and social attitudes have begun to favor male nurses. Aiming at the bad states of nursing students, the lack of update nursing teaching, as well as the problems of male nursing students' characteristic development, the paper puts forward some effective measures to create a new type of male nurse concept, deepens the ideological concept of education, and strengthens the construction of nursing curriculum reform of nursing education.
\end{abstract}

Keywords-Male nursing students; Professional advantages; Training difficulties; Nursing education

\section{INTRODUCTION}

With The development of medical and health services, the change of disease spectrum, and the improvement of people's demand for health care have put forward diversified and high quality requirements for nursing staff. With the concept of nursing and clinical nursing update requirements, select the nursing professional boys increased, the social development and the development of nursing science in male nurses to nursing posts, male nurses continue to inject new vitality into the nursing career, has played an important role in the society. Men have obvious advantages in nursing occupation, but there are still gaps in the number of male nurses in hospitals. Our higher nursing education since 1980s, the number of rapid growth, due to competition and the vigorous development of the nursing profession of nursing undergraduate nursing education between colleges and universities intensifies, how to maintain a competitive advantage, only by virtue of the size, funding, has been difficult to adapt to the new requirements of the development. Strengthening the connotation construction, making nursing education run its own characteristics and advantages, and creating core competitiveness has become a new thinking point. It is imperative to study the reform of nursing education. The teaching quality and teaching level, is an important manifestation of the comprehensive strength of the professional, is the basic education to attract students, forming social status, is a professional image and an important way to improve the visibility.

Highly educated and highly qualified male nurses are well received by hospitals and the general public, but there are many problems in the education and learning status of male nursing students. Guo Jiao (2011), through a survey of male nursing students graduating from 34 medical colleges, concluded that only 7 male students were enrolled in the nursing profession independently, and the other male nursing students were partly constrained by the limit of performance, and the other was forced to choose for other reasons. Zhou Ping and so on (2012) investigated the learning situation of 80 specialist male nursing students. Through data analysis, it was found that only $2.5 \%$ of the students chose the major because they preferred to engage in nursing profession, and $62.5 \%$ of the male nursing students chose the major because of the better employment in the nursing profession. It can be seen that the male nursing students are hot on the nursing profession. The feeling is not high. From the perspective of school nursing education, because of the uniqueness of the male nursing students in the course of interest, career pursuit and the image of nurses, the education and teaching mode and curriculum design for the female nursing students before the majority of nursing colleges and universities are difficult to meet the needs of the male nursing students' learning and development, and can not meet the needs of the male nursing students. Therefore, combing the occupational advantages of male nursing students and analyzing their training predicament, laying a solid foundation for optimizing nursing education for male nursing students has become a topic worthy of attention and research. 


\section{ANALysis OF The OCCUPATIONAL AdVANTAGES OF MALE NURSING STUDENTS}

Because of gender differences, male nursing students have obvious advantages in nursing work. Men have more agile thinking ability, more rapid action response, stronger physical quality and more stable character. Therefore, they are more adaptable to intensive care and homosexual nursing needs, and their professional advantages are embodied in the following three aspects.

\section{A. Meeingt the needs of high intensity work}

Nursing is a very labor intensive work, requiring staff to have strong physical strength. From this point of view, men have certain advantages in nursing profession. It is more obvious that the care of 120 emergency, surgical and emergency patients, the movement of the paralyzed patients, the lifting of critical patients, the patient's turn over and traction, and so on, need the strong physical strength of the nursing staff. In prolonged operation and obstetrics and Gynecology, the strength of male nurses can be exerted by coping with prolonged work intensity and shifting to pregnant women.

\section{B. Adapting to the needs of homosexual nursing operation}

Some special operations in the urology department have a strong demand for the male nurses. The demand for the patients and their families is increasing. The demand for male nurses is obvious in the aspects of male patients' urethral catheterization, the examination of the privacy part and the nursing assessment. The same sex care helps to eliminate the gender differences between the nurses and the nurses. Resulting in tension or embarrassment, can effectively relieve the psychological pressure of patients, make nursing operation more smoothly, and promote the recovery of patients.

\section{Adapingt to the demand of rational psychological quality}

Compared with women, male psychological quality is better, more heroic and courageous, especially in the face of accidents such as bloody scenes, male nurses are more frank; face to hospice care, their psychology The ability to bear and the ability to cope more can highlight the advantages, the operation is more calm and not disorderly, in the implementation of emergency, on-site emergency and intensive care and other nursing operations, the control and communication ability of male nurses all reflect certain advantages.

\section{An Analysis Of The Plight Of Male Nursing STUDENTS}

The development of social development and nursing work has increased the demand for male nurses, and the male nursing students are also showing a trend of growth. However, the training of the male nursing students, such as the deeprooted image of the female nurses, has caused the psychological pressure of the male nursing students; the social concept is biased, which leads to the undesirable feelings of the male nursing students and so on, from the perspective of school education. Because the traditional nursing education is mainly aimed at the girls, there is no curriculum content for the male characteristics, and the later nursing course teaching has not been updated in time, which hinders the development of the male nursing students' professional characteristics.

\section{A. The image of female nurses is deep-rooted, resulting in psychological stress of male nursing students}

Florence Nightingale (Florence Nightingale), founder of nursing career and founder of modern nursing education, attaches great importance to the beauty of nursing professional image, thinks that it is the necessary condition for the social psychological environment needed by the patient, the beautiful image in the process of nursing implementation, from the perspective of the patient, for patients to be diagnosed. Rehabilitation and rehabilitation provide a favorable environment. From the perspective of nursing staff, the professional pursuit of nursing staff is actively guided through the edification and pursuit of beauty. For a long time, the public's understanding of nurses' professional identity and professional image has a feminine aura. From the original image of Nightingale's Saint daughter to the style color design of the nurse's clothes, and then to the nurse's etiquette standard and posture, a more systematic standard has been formed. In the public opinion, the nurse is the equivalent of the female. In contrast, the male nurse and the male nurse have no symbolic dress and etiquette rules. The male nurses are sometimes mistaken for doctors in their work, and the degree of professional identity is reduced, and the difficulty and pressure of the work of male nurses are increased.

\section{B. Biased Social attitudes leading to bad feelings for male nursing students}

Because of the influence of traditional concepts, salary and social status, male nurses are hard to get support and understanding from their families. In the daily media publicity, women are also representatives of nurses, which also reduces the professional identity of male nurses, and adds trouble to male nurses. In social interaction, male nurses can not receive due respect and recognition, and bear more pressure than female nurses. It is difficult for male nurses to realize the satisfaction of self value identification, and it is difficult to be optimistic about their own career development. These factors have caused the bad experience of the male nursing students and are not conducive to the cultivation of the male nursing students.

\section{The lack of updating nursing curriculum hindering the development of male nursing students}

The traditional nursing standards and nursing education are mainly designed from the perspective of women. There is no consideration of the standard of nursing and the implementation of education from the male characteristics. It lacks the design of the thinking problems and practical measures for the male in nursing. The lack of updating of nursing curriculum design and teaching content hinders the development of male nursing students and is not conducive to the development of nursing education. 


\section{THE OPTIMIZATION OF NURSING EDUCATION FOR MALE NURSING STUDENTS}

\section{A. Creating a new image of male nurses}

Creating a new male nurse image can not only comb the learning examples of male nursing students, but also help enhance the professional identity and self confidence of male nursing students. In order to improve the enthusiasm and comprehensive quality of the male nurse, we should draw on the actual needs of the nursing work in our country and standardize the male nurse's etiquette and work uniforms.

\section{B. Deepening the ideological and Ideological Education}

It is of great significance to do a good job of Ideological and ideological education during the school period and to guide the male nursing students actively. It is also helpful to organize the study activities of the male nursing students regularly, to share the fun of study, to pour out the troubles and anguish produced by their professional sex, and to form a good atmosphere for the male nursing students to learn long. In the form of the propaganda column, it reports the advanced deeds of the male nurses, and regularly invites the male nurses who have made outstanding achievements in the work to carry out the lectures, which will help the male nurse's learning goals to be more visualized, relieve the psychological pressure and enhance the motivation of learning.

\section{Strengthening the teaching of characteristic courses}

The course teaching is the basic way and core link for the male nursing students to accept the nursing knowledge and the vocational training. The traditional course teaching can lack the teaching content which is specially aimed at the male nursing students. The male nursing students are more suitable for the emergency, the urology department and the Jing Shen Department because of their physiologic, psychological and physical characteristics, and they are more rational and strong. In the Department, the school should adopt the form of expanding the professional direction or elective and other forms to strengthen the learning knowledge of the male nursing students. In addition, we should pay more attention to the teaching of the practice, practice and practice of the male nursing students in school, strengthen the proportion of the practice teaching, and strengthen the moral education of the nursing students and the legal law in practice. Compliance education content, so as to improve the comprehensive quality and occupation ability of male nursing students.

\section{Paying attention to the career planning of the male nursing students}

According to the definition of Chinese career planners Association, career planning for college students refers to the systematic career planning process of university students. It includes students' Learning Planning and career planning during the University. There is no occupation career planning and planning is reasonable, the quality of life during the study not only directly affect college students, but also directly affect the students after graduation employment and even the future occupation career development trend. Therefore, the school of nursing education should be aimed at nursing occupation the important reserve forces of male nursing students for specialized research, to help them develop systematic nursing occupation career planning, to help men do the occupation choice and sustainable development in the future of nursing students.

\section{CONCLUSIONS}

With the progress of the society and the gradual improvement of the people's living standards, the public has paid more and more attention to the health of the body, put forward higher requirements for the quality of nursing service, and brought new opportunities and challenges to the nursing work and nurses. For a long time, the current situation of women's nursing work has been unable to meet the needs of the society and the masses. The male nurses have increased the demand for male nurses because of their unique advantages such as quick thinking ability, quick action response, strong physical quality and stable character characteristics, so that the male nurse can give full play to the male nurse. It is necessary to strengthen nursing education and pay attention to the education of male nursing students in Colleges and universities. In the implementation of nursing education, colleges and universities should build new male nurses, deepen ideological and concept education, strengthen the teaching of special courses and so on, improve nursing education, eliminate the psychological pressure and bad of male nurses. Feelings, enhance their learning enthusiasm and initiative.

\section{ACKNOWLEDGMENT}

The national innovation training project, the results of the survey on the professional cognition and employment development of male nurses in the school (201613324052).

Supported by scientific research team of Shandong Xiehe University.

\section{REFERENCE}

[1] Li Shuguang, Wang Fu, Xue Ling. Psychological health status of male nurses in the psychiatric department of the three year follow-up survey and analysis of $[\mathrm{J}]$. Modern Nursing, 2002, 08.

[2] Yao Ying, Zhu Lan Jian. The clinical practice and thinking of male nurses. Nursing Practice and Research. 2008,05.

[3] Peng Chaohua, Lu Yongmei, Sun Qiongyang, Cheng Meng Hui, Cai Min. Qualitative research on professional identity of male nursing students in Chinese medicine colleges and universities [J]. Qilu Nursing Journal, 2018, 02 .

[4] Sun Xueqin, Wang Chunmei, Xu Huashan, Zou Bing. Factors influencing subjective well-being of 392 male undergraduate nursing students [J]. Chinese Journal of Health Psychology, 2017, 04.

[5] Sun Mengxin, Gu Zijuan, Wang Xiao, Huang Yuqin, Zhu Peiyun. Investigation and analysis of the factors related to the job loss of male nursing students [J]. Nursing Research, 2017, 02.

[6] Chen Simeng, Qi Jia Yan, Ni Qingqing, Zhou Fang, Xu Hongbo. The relationship between the self abasement of male nursing students and their relationship with personality characteristics and social support [J]. Nursing and Rehabilitation Journal, 2016, 05.

[7] Zhao Mingzhu, Zhang Yaqing, Li Shasha. Investigation and analysis of clinical use of male nurses [J]. Shanghai Nursing, 2002, 02.

[8] Guo Jiao. Analysis of the causes of the turnover intention of nursing undergraduate male nurses and countermeasures [J]. Nursing Practice and Research, 2011, 08.

[9] Zhou Ping, Zhang Chunmei, Ni Ruiju. Analysis of learning motivation of the students in Higher Vocational Colleges of nursing male [J].Journal of Qiqihar University Of Medicine, 2012, 33. 